\title{
Desarrollo de las TIC en el turismo de nieve: Análisis de la presencia en línea de las estaciones de esquí de España y Andorra
}

\author{
Natalia Daries-Ramon \\ Eduard Cristóbal-Fransi \\ Eva Martín-Fuentes \\ Estela Mariné-Roig \\ Universitat de Lleida. Departamento de Administración de Empresas \\ ndaries@aegern.udl.cat \\ ecristobal@aegern.udl.cat \\ eva@aegern.udl.cat \\ estela.marine@aegern.udl.cat
}

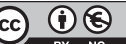

Recepción: octubre de 2015

Aceptación: junio de 2016

\section{Resumen}

La presente investigación busca conocer si los sitios web de las estaciones de esquí de España y Andorra facilitan una comunicación eficaz con sus públicos objetivo. Para ello, se propone y se aplica un modelo para el análisis de las páginas web de las estaciones de esquí, basado en la técnica de análisis de contenido, considerando las dimensiones de información, comunicación, comercio electrónico y funciones adicionales. Este modelo se aplicó a la totalidad de las estaciones de esquí y montaña de España y Andorra: 31 alpinas, 21 nórdicas y 1 cubierta. Los resultados indican que las estaciones de esquí alpino están mejor preparadas que las de esquí nórdico, a pesar de que todavía tienen mucho recorrido por hacer a la hora de facilitar una comunicación y una interacción efectivas con su público objetivo.

Palabras clave: TIC; turismo de nieve; comercio electrónico; estación de esquí; análisis del contenido web

Resum. Desenvolupament de les TIC en el turisme de neu: Anàlisi de la presència en línia de les estacions d'esquí a Espanya i Andorra

La present investigació busca conèixer si els llocs web de les estacions d'esquí d'Espanya i d'Andorra faciliten una comunicació eficaç amb els seus públics objectiu. Per aquest motiu, es proposa i s'aplica un model per analitzar les pàgines web de les estacions d'esquí, basat en la tècnica d'anàlisi de contingut i considerant les dimensions d'informació, comunicació, comerç electrònic i funcions addicionals. Aquest model es va aplicar a la totalitat de les estacions d'esquí i de muntanya d'Espanya i d'Andorra: 31 d'alpines, 21 de nòrdiques i 1 de coberta. Els resultats indiquen que les estacions d'esquí alpí estan més ben preparades que les d'esquí nòrdic, malgrat que encara tenen molt de recorregut per fer a l'hora de facilitar una comunicació i una interacció efectives amb el seu públic objectiu.

Paraules clau: TIC; turisme de neu; comerç electrònic; estació d'esquí; anàlisi del contingut web 
Résumé. Le développement des TIC dans le tourisme de neige: Analyse de la présence en ligne des stations de ski en Espagne et Andorre

Cette recherche vise à savoir si les sites web des stations de ski en Espagne et en Andorre fournissent une communication efficace avec leurs publics cibles. À cette fin, nous proposons et appliquons un modèle pour l'analyse des sites web des stations de ski fondé sur la technique d'analyse du contenu, en considérant les aspects de l'information, de la communication, du commerce électronique et des fonctions supplémentaires. Ce modèle s'applique à toutes les stations de ski de l'Espagne et de l'Andorre: 31 de skialpin, 21 de ski nordique et 1 indoor. Les résultats indiquent que les stations de ski alpin sont mieux préparées que celles de ski nordique bien qu'elles aient encore beaucoup de chemin à parcourir pour faciliter unecommunication efficace et l'interaction avec leur public cible.

Mots-clés: TIC; tourisme de neige; commerce électronique; station de ski; analyse de contenu web

Abstract. ICT development in snow tourism: Analysis of the online presence of ski resorts in Spain and Andorra

The aim of this study is to analyse whether the websites of ski resorts in Spain and Andorra facilitate effective communication with their target audiences. To this end, we propose and implement a model for the analysis of ski resort websites based on the content analysis technique, considering the dimensions of Information, Communication, E-commerce and Additional Functions. This model applies to all ski resorts of Spain and Andorra: 31 Alpine, 21 Nordic and 1 Indoor. The results indicate that alpine ski resorts are better prepared than Nordic ski resorts although they still have a long way to go in order to facilitate effective communication and interaction with their target audiences.

Keywords: ICT; snow tourism; e-commerce; ski resorts; web content analysis

\section{Sumario}

1. Introducción 4. Resultados

2. Turismo de nieve

5. Conclusiones

3. Metodología: modelo de análisis

Agradecimientos

del contenido web

Referencias bibliográficas

\section{Introducción}

La irrupción de las nuevas tecnologías en general y de Internet en particular ha influido en la forma de gestionar y de competir de las empresas siendo el sector turístico uno de los más afectados y donde se ha observado un proceso de adopción más generalizado (Dijkmans et al., 2015). Uno de los aspectos donde más han impactado las nuevas tecnologías de la información y la comunicación (TIC) ha sido en la manera en que las empresas turísticas distribuyen sus pro- 
ductos en el mercado (Buhalis, 2000; O'Connor y Frew, 2000). Por tanto, las TIC contribuyen no solo a facilitar cambios económicos, sino también cambios sociales y culturales (Chang y Chuang, 2011; Jacobsen y Munar, 2012), como se está observando en los últimos años con el uso de nuevos dispositivos como teléfonos inteligentes o tabletas digitales, por ejemplo, y que, lógicamente, tiene su influencia en el auge del comercio electrónico (DiPietro y Wang, 2010).

En consecuencia, y debido a este nuevo escenario, los consumidores utilizan cada vez más Internet como fuente de información sobre productos y servicios turísticos, como reservas hoteleras, alquiler de coches, vuelos, paquetes turísticos, etc. (Cristóbal-Fransi et al., 2013), de la misma forma que está aumentando también la proporción de alojamientos y de viajes contratados a través de la red (Litvin et al., 2008; Pérez Pérez et al., 2002).

El uso de las TIC tiene una incidencia especial en la innovación en el sector turístico, lo cual da lugar a la investigación y al desarrollo de nuevos productos (Hjalager, 2010). Por otro lado, tenemos que tener en cuenta que la innovación no solo se consigue incorporando tecnología, sino también gestionándola correctamente. A nivel de comportamiento de los usuarios de servicios turísticos, los hábitos de compra y de consumo de los individuos también se han visto influenciados por las nuevas tecnologías (Kim y Fesenmaier, 2008; Filieri y McLeay, 2014). De hecho, Internet permite que el consumidor sea cada vez más exigente y que esté mejor informado, y por ello asume cada vez más la gestión de sus viajes y desplazamientos (Law y Bai, 2008).

El principal uso que dan las pymes y las grandes empresas turísticas a las redes sociales es su integración en las estrategias de marketing, así como el contacto y la información con los clientes. . El trabajo realizado por Chung y Buhalis (2008) señala la importancia que tienen en el consumo turístico el uso de las redes sociales y las comunidades en línea. Los resultados que obtienen muestran que las empresas que desarrollan comunidades en línea generan mayores beneficios y posibilidades de negocio, además de una mayor fidelidad de los consumidores. Asimismo, del estudio, se desprende que la mayoría de los usuarios de estas comunidades las perciben como útiles, puesto que satisfacen sus necesidades de información gracias a las opiniones, las recomendaciones y las comparativas que se pueden encontrar en ellas.

Una vez vista la significativa influencia de las tecnologías de la información y de la comunicación en la gestión de las empresas turísticas y en el comportamiento de los consumidores de productos y servicios turísticos, consideramos necesario evaluar la presencia y el uso de Internet en un sector territorialmente y económicamente tan importante y estratégico como el turismo de nieve, a través del análisis del contenido web de las estaciones de esquí. Por ello, el principal objetivo del presente trabajo es analizar, a través de la observación de los sitios web, si se aprovechan las posibilidades de la web y de la web 2.0 por parte de los estaciones de esquí de España y de Andorra. Por otro lado, y teniendo presente que algunas estaciones de esquí se encuentran en un proceso de transformación hacia estaciones de montaña ante un escenario de reducción de la actividad de los deportes de invierno a consecuencia de los efectos del 
cambio climático, es de vital importancia que estas empresas sean capaces de comunicar dichos cambios a sus clientes a través de las diferentes posibilidades que aporta Internet.

Esta investigación de tipo exploratorio permitirá identificar en profundidad cuál es la situación actual de los sitios web en este tipo de instalaciones turísticas de nieve. En España, son escasos los estudios que identifiquen estos aspectos desde una perspectiva de marketing y con este nivel de detalle aplicados al sector del turismo de nieve y de montaña. El presente estudio pretende:

- Proponer un modelo para evaluar el contenido de los sitios web de estaciones de esquí en base a las cuatro categorías de contenido: información, comunicación, comercio electrónico y funciones adicionales.

- Utilizar el modelo propuesto para analizar los sitios web de la totalidad de las estaciones de esquí en España y Andorra.

- Proporcionar recomendaciones y sugerencias para una gestión más eficiente de la presencia en línea de las estaciones de esquí, para ver hasta qué punto utilizan las potencialidades de las TIC para la comunicación con sus públicos a través de sus webs y poder aportar recomendaciones prácticas de mejora.

\section{Turismo de nieve}

El turismo de nieve lo podemos englobar dentro del turismo deportivo y del turismo de naturaleza, ya que esta disciplina se genera motivada por el deseo de practicar actividades deportivas en un entorno natural, de nieve y montaña (Esteban, 1995). Por otro lado, Saz y Carús (2008) acuñan el concepto de «segmento turístico recreativo de alta montaña» (STRAM) y lo definen como «el formado por Centros Turísticos Recreativos de Alta Montaña (CTRAM) o destinos que a través de una inversión previa en recursos humanos, equipos e infraestructura diversa explotan en ubicaciones de alta montaña, también fuera de la época invernal, centros recreativos o de ocio».

A nivel territorial, la oferta española de turismo de nieve y de montaña representa un total de 1.039 kilómetros de pistas esquiables, una cifra que llama la atención al compararse con los 3.168 km de costa española. Para contextualizar el sector, es interesante visionar el mapa topográfico de la Península ibérica elaborado por ATUDEM (Asociación Turística de Estaciones de Esquí y Montaña), en el que se aprecia la distribución espacial de las diferentes estaciones, en todas las cordilleras de la Península con elevación considerable sobre el nivel del mar. Así, vemos que las estaciones de esquí están distribuidas entre un gran número de comunidades autónomas (Andalucía, Aragón, Asturias, Cantabria, Castilla-León, Cataluña, Madrid, Galicia, La Rioja y Navarra).

La mayoría de las estaciones de esquí se circunscriben en la modalidad de estaciones de esquí alpino, pero un gran número de las estaciones enumeradas en este mapa son, a su vez, estaciones de esquí nórdico. El esquí alpino es la modalidad más conocida, que consiste en descender por una montaña 
Figura 1. Mapa de las estaciones de esquí en España

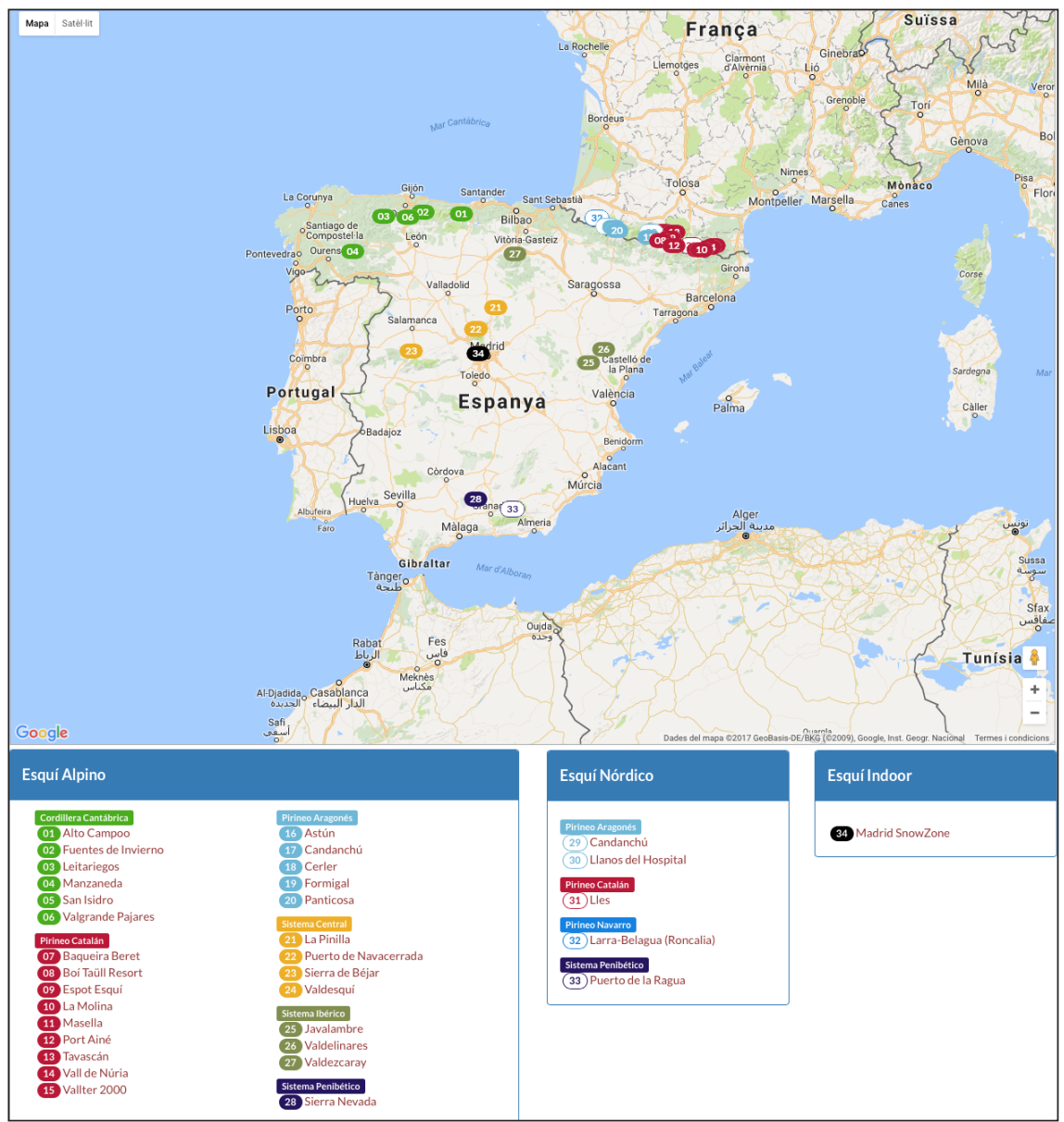

Fuente: ATUDEM (2017). Mapa de ubicación de las estaciones de esquí españolas. Documento disponible en: <http://www.atudem.es/mapa_ubicacion.aspx>.

nevada, mientras que el esquí nórdico consiste en desplazarse de un sitio a otro. Dentro del sector, las estaciones de esquí nórdico suponen un porcentaje significativamente inferior, tanto a nivel numérico como económico. A pesar de ello, todas forman parte de los recursos turísticos de las zonas donde se ubican y tienen una clara utilidad como modo de aproximación a los deportes de invierno.

En conjunto, las estaciones de esquí españolas representan un sector económico en alza que, en los últimos diez años, ha invertido más de 700 millones de euros en mejoras de sus instalaciones y cuenta con un creciente número de deportistas y turistas que las visitan o que realizan jornadas de esquí en 
ellas. Este sector desarrolla, a su vez, actividades económicas colaterales, como transporte, hostelería, comercio de ropa y complementos, alquiler y venta de material deportivo, etc. (García Abad, 2012).

Tal y como afirma Lasanta Martínez (2010) en su estudio sobre el Pirineo aragonés, los municipios con estaciones de esquí incrementan su población, el número de trabajadores en el sector terciario es muy elevado y, en cambio, apenas conservan activos en el sector primario. Estos territorios siguen la tendencia de regiones alpinas con gran presencia de la industria turística (Pechlaner y Tschurtschenthaler, 2003).

Según datos de ATUDEM (2015), el número de visitantes de las estaciones de esquí supera los cinco millones de personas y todos ellos disfrutan de una oferta de alojamiento de más de 217.000 plazas. Por tanto, los datos que documentan el flujo de turistas hacia las zonas de montaña ponen de manifiesto que el sector ha cobrado una importancia económica determinante (Martínez et al., 2014).

Siguiendo el trabajo de Falk (2010), la demanda de turismo de invierno depende de diversos factores: la renta nacional e internacional, los precios, el transporte, los costes, la ubicación de las vacaciones de Pascua y el cambio climático.

A pesar de que el cambio climático es solo uno de los factores que influyen en el turismo de invierno, la presencia o ausencia de nieve, en concreto, el espesor de nieve y su temporalidad, son elementos clave a la hora de valorar la viabilidad y la sostenibilidad del sector a medio y a largo plazo (Saurí y Llurdés, 2010; López-Moreno et al., 2013; Pons et al., 2014). La mayoría de autores que han dedicado sus esfuerzos al estudio del impacto del cambio climático (López-Moreno et al., 2008; Romagosa et al., 2011; March et al., 2014) coinciden en señalar que sus efectos son más evidentes en la actualidad en el turismo de invierno que en el caso del turismo de sol y playa, y que también es más patente su dificultad de adaptación. En general, las zonas de montaña afectadas se muestran más vulnerables que las zonas costeras y las islas, que incluso podrían aprovechar el cambio climático para desestacionalizar la demanda.

Los efectos del cambio climático en el turismo de invierno suponen el acortamiento de la temporada y el aumento del uso de la innivación artificial, dada la escasez de nieve en las zonas de baja altitud de las montañas del Pirineo catalán, sobre todo para algunas estaciones de esquí orientadas hacia el sur (López-Moreno et al., 2013), lo que conlleva un incremento considerable en los costes de producción y el aumento de recursos hídricos. Por otro lado, en el cuarto informe del Panel Intergubernamental sobre el Cambio Climático (IPCC), se afirma que «el impacto del cambio climático sobre la industria del turismo deportivo de nieve es potencialmente grave» (Calbó et al., 2012: 17).

En un trabajo de Saurí y Llurdés (2010) donde se evalúa el turismo dentro del segundo estudio sobre el cambio climático en Cataluña junto con los informes sobre el cambio climático del Consell Assessor per al Desenvolupament Sostenible (CADS), se señala que la temperatura media de Cataluña ha crecido en torno a $0,9^{\circ} \mathrm{C}$ a lo largo del siglo $\mathrm{XX}$, pero las previsiones para el siglo XXI son 
Tabla 1. Cifras de las estaciones de esquí alpino

\begin{tabular}{|c|c|c|c|c|c|c|c|c|c|}
\hline Temporada & $2004-200$ & 2005-2006 & 2006-2007 & $2007-2008$ & $2008-2009$ & $2009-2010$ & 2010-2011 & 2011-2012 & 2012-2013 \\
\hline Número de visitantes & 6.254 .715 & 7.165.109 & 4.559 .144 & 5.160 .195 & 6.657 .778 & 5.618 .059 & 5.541 .159 & 4.505 .715 & 5.110 .000 \\
\hline $\begin{array}{l}\text { Capacidad total de } \\
\text { transporte (persona/hora) }\end{array}$ & 384.858 & 392.182 & 421.660 & 459.747 & 467.677 & 456.748 & 454.852 & 449.457 & 460.300 \\
\hline Pistas balizadas $(\mathrm{km})$ & 887 & 888 & 953 & 332 & 1.036 & $1.007,42$ & $1.011,96$ & $1.026,82$ & $1.039,50$ \\
\hline $\begin{array}{l}\text { Producción de nieve } \\
\text { artificial }(\mathrm{km})\end{array}$ & 274 & 292 & 321 & 333 & 358 & 339 & 349 & 365 & 375 \\
\hline Oferta de alojamiento ${ }^{1}$ & 133.153 & 163.996 & 174.138 & 176.482 & 220.026 & 216.452 & 213.699 & 240.911 & 217.400 \\
\hline $\begin{array}{l}\text { Inversiones } \\
\text { (miles de euros) }\end{array}$ & 11.845 & 73.056 & 99.510 .291 & 72.596 .173 & 50.365 .331 & 54.291 .895 & 59.724 .303 & 24.372 .277 & - \\
\hline
\end{tabular}

Nota: Hoteles, apartamentos, albergues y casas rurales, incluida su área de influencia (radio = $35 \mathrm{~km}$ ).

Fuente: elaboración propia a partir de ATUDEM (2015).

aún más alarmantes. Además, se prevén notables transformaciones en el clima del Pirineo catalán que afectarán, con seguridad, a la pluviometría y la innivación de la región y, por tanto, al turismo de montaña (Puig y Freire, 2012).

De esta manera, dada la incertidumbre de la continuidad de algunas estaciones de esquí a medio y largo plazo, debido a los cambios en el clima, las empresas invierten sobre todo en estaciones de esquí de altura con el objetivo de crear grandes dominios esquiables (Gerbaux y Marcelpoil, 2006; Falk, 2009) para atraer a esquiadores extranjeros (franceses, ingleses y rusos).

En una economía globalizada, por tanto, las estaciones de esquí españolas se ven afectadas por nuevos competidores como pueden ser las instalaciones situadas en los países de Europa del Este, que ofrecen nuevas infraestructuras y precios atractivos. Los gerentes de las estaciones de esquí españolas deben enfrentarse al envejecimiento de sus instalaciones. De hecho, un dominio esquiable se caracteriza por la infraestructura técnica para la práctica del esquí, esto es: pistas, senderos, aseos, equipos de nieve artificial, taquillas e instalaciones de recepción (Gonçalves, 2013).

Según Matzler y Siller (2003), las motivaciones del viajero y la capacidad percibida acerca de un punto concreto para satisfacer las expectativas previas son variables estratégicas en el marketing de destinos. Estos autores se centran en las motivaciones de jóvenes turistas alemanes respecto a lugares de montaña $\mathrm{y}$, entre otras cosas, diferencian las motivaciones para los viajes de verano y los de invierno. En invierno, estos viajeros se muestran mucho más activos y buscan ofertas más estimulantes, como las relacionadas con el deporte y la diversión. Quieren disfrutar del paisaje, la naturaleza y conocer gente. En cambio, en verano, cobran más importancia aspectos como la vida en la naturaleza y la relajación. Para estos jóvenes turistas, motivaciones relacionadas con actividades culturales, tradicionales o de lujo y confort pasan a ser secundarias, tanto en verano como en invierno. En esta línea, Pearce (2006) propone que, en la decisión de viajar a una estación de esquí en invierno, intervienen tanto los aspectos internos - las características del individuo y los motivos personales - como los aspectos externos — las características del destino-. Por un 
lado, el viajero quiere realizar un conjunto de actividades que le permita llevar a la práctica una serie de experiencias deseadas. Por lo tanto, las actividades disponibles en el destino afectan a su elección. De ello, podemos extraer que la manera como las estaciones de esquí comuniquen las actividades que realizan es clave para que el viajero se decida por una o por otra.

Por último, y si nos centramos en el estudio de Internet y el turismo de nieve, podemos destacar el trabajo realizado por García-Lastra y Escalera (2008), donde se analizaba la implantación y el uso de las herramientas de comercio electrónico en las estaciones de esquí de España y Andorra a través de la metodología eMICA (Extended Model of Internet Commerce Adoption) desarrollada por Burgess y Cooper (1998). Este modelo propone que, en el desarrollo de sitios web comerciales, las empresas suelen iniciarse en Internet a través de una simple página web y que esta presencia se hace más compleja con el tiempo, puesto que su experiencia y sus conocimientos en el uso de las TIC aumenta, y ello provoca que incorporen nuevos procesos. La metodología eMICA consta de tres etapas e incorpora tres niveles de procesos de negocio: $a$ ) la promoción basada en la web; $b$ ) el suministro de información y servicios, y $c$ ) el proceso de transacciones. Las etapas de desarrollo proporcionan una hoja de ruta que indica en qué nivel se ubica un sector de negocio en su desarrollo de aplicaciones de comercio electrónico. Los resultados de su investigación mostraron que los sitios web de las estaciones de esquí presentaban un grado medio-bajo de madurez funcional. En nuestro caso, la metodología es diferente y el objetivo a alcanzar también. El objetivo no es únicamente conocer el nivel de adopción del comercio electrónico por parte de las estaciones de esquí de España y Andorra, sino que la finalidad es más amplia, ya que se busca saber, a través de la observación de los sitios web, si se aprovechan sus posibilidades, así como las de la web 2.0. Para ello, se desarrolla un modelo para evaluar el contenido de los sitios web de las estaciones de esquí en base a cuatro categorías de contenido: información, comunicación, comercio electrónico y funciones adicionales.

Dada la situación tan delicada a la que se están enfrentando gran parte de las estaciones de esquí del Pirineo Catalán y Andorra, es de gran importancia que sus páginas web transmitan información actualizada, fiable y de calidad, para que sus usuarios conozcan el estado real de sus instalaciones.

\section{Metodología: modelo de análisis del contenido web}

Debido a la gran importancia que tiene el sitio web como elemento de comunicación y de representación de una organización, la elaboración de una metodología adecuada para la evaluación de las características ideales de una web es un tema de gran interés para los investigadores y los profesionales. Después de revisar la literatura, diferentes autores corroboran que no existe una metodología universalmente reconocida para evaluar un sitio web (Baggio et al., 2011; Law et al., 2010).

Los métodos más frecuentes de investigación en cuanto a la evaluación de los sitios web se basan fundamentalmente en encuestas, evaluación experimen- 
tal y análisis de contenido (Chiou et al., 2010). Según Law et al. (2010), los enfoques metodológicos más utilizados en la investigación sobre la medición de sitios web en el turismo se dividen en cinco clases diferentes: 1) método de contabilización; 2) método automático; 3) método de computación numérica; 4) método de opinión de usuarios, y 5) método combinado. En el caso de la presente investigación se utilizará el método de contabilización.

En cuanto al enfoque del análisis, una gran número de estudios hacen referencia a una serie de indicadores que podemos agrupar en cuatro grandes tipos: técnicos, comerciales, relacionados con el contenido y relacionados con el diseño (Cristóbal-Fransi, 2006; Chiou et al., 2010; González et al., 2013). Desde la perspectiva de la orientación al mercado, se evalúa los sitios web identificando a los usuarios como clientes potenciales, por lo cual los evaluadores se centran más en aspectos relacionados con la promoción de las actividades, las transacciones en línea y los detalles de los productos y servicios (Álvarez, 2014). En el presente trabajo, se ha optado por utilizar esta perspectiva de investigación.

Con el objetivo de elaborar un modelo para estructurar el análisis del contenido web aplicado a las estaciones de esquí, se ha realizado una revisión de la literatura existente (Álvarez, 2014; Baloglu y Pekcan, 2006; Bingley et al., 2010; Chung y Law, 2003; Escobar y Carvajal, 2013; Lee y Morrison, 2010; Schegg et al., 2002; Woodside et al., 2011) y se propone el siguiente modelo (ver tabla 2), el cual nos aportará una visión de los recursos que las estaciones de esquí muestran en sus sitios web para que sus usuarios obtengan la información necesaria y les permita interactuar con las mismas, ya sea para realizar actividades de comercio electrónico (compra de forfaits, servicios de restauración, alquiler de material, etc.), ya para plantear cuestiones en una plataforma segura que garantice el cumplimiento de los estándares de calidad de un sitio web.

El modelo presentado está compuesto por cuatro bloques de análisis de las páginas web: información, comunicación, comercio electrónico y funciones adicionales, tal como se muestra en la tabla 2. Cada uno de los bloques tiene sus propias características e ítems a evaluar. Los indicadores de evaluación aparecen recogidos en las tablas 3, 4, 5 y 6 para las dimensiones de información, comunicación, comercio electrónico y otras funciones, respectivamente.

\subsection{Información (I)}

El turismo es un sector que realiza un uso intensivo de la información (Cristóbal-Fransi et al., 2013). Una de las razones fundamentales es la distancia existente entre el lugar de residencia del turista y el destino al que se desplaza (Álvarez, 2014). Como consecuencia, es clave establecer unas vías de comunicación adecuadas para transmitir al turista la información necesaria sobre el destino en concreto. Por tanto, la difusión de la información se convierte en uno de los principales objetivos de los sitios web de promoción turística. Por esta razón, se incluye esta variable de información donde se evalúa la presencia de aspectos relativos a la información disponible alrededor de cuatro categorías: 
Tabla 2. Modelo propuesto de análisis del contenido web de las estaciones de esquí

\begin{tabular}{lll}
\hline Dimensiones & \multicolumn{1}{c}{ Definición } & \multicolumn{1}{c}{ Autores } \\
\hline Información & Esta dimensión evalúa la información & Álvarez (2014), Baloglu y Pekcan \\
& disponible en los sitios web de las & (2006), Bingley et al. (2010), Cantoni et \\
& estaciones de esquí y la facilidad & al. (2011), Chiou et al. (2011), Chung y \\
& por parte del usuario de encontrarla. & Law (2003), Davidson (2007), \\
& & Escobar y Carvajal (2013), Heinze y Hu \\
& (2006), Lee y Morrison (2010), Liao et \\
& al. (2006), Robbins y Stylianou (2003), \\
& Schegg et al. (2002), Schmidt et al. \\
& (2008), Woodside et al. (2011).
\end{tabular}

Comunicación Esta dimensión mide la capacidad que tiene el sitio web de interactuar con los clientes, ya sea a través de mecanismos de comunicación, recursos web 2.0 o disponibilidad de información en diferentes idiomas.
Álvarez (2014), Baloglu y Pekcan (2006), Bingley et al. (2010), Cantoni et al. (2011), Chiou et al. (2011), Chung y Law (2003), Davidson (2007), Escobar y Carvajal (2013), Heinze y Hu (2006), Huertas y Marine-Roig (2015), Lee y Morrison (2010), Schegg et al. (2002), Schmidt et al. (2008), Sigala (2012), Walcott (2007), Woodside et al. (2011).

Comercio electrónico Esta dimensión evalúa la competencia
del sitio web para desarrollar actividades comerciales seguras.

Álvarez (2014), Cantoni et al. (2011),

Chiou et al. (2011), Chung y Law (2003), Escobar y Carvajal (2013), Lee y Morrison (2010), Schegg et al. (2002), Schmidt et al. (2008), Ting et al. (2013), Woodside et al. (2011).

\begin{tabular}{lll}
\hline Funciones & Esta dimensión mide la capacidad & Álvarez (2014), Davidson (2007), Kim \\
adicionales & del sitio web para transmitir seguridad & et al. (2015), Ting et al. (2013), Walcott \\
& $\begin{array}{l}\text { a través de elementos de protección } \\
\text { de datos y certificaciones y el uso de }\end{array}$ & (2007). \\
& $\begin{array}{l}\text { nuevos medios como la versión móvil } \\
\text { de la web o de sus aplicaciones. }\end{array}$ & \\
&
\end{tabular}

Fuente: elaboración propia.

1) información sobre las estaciones de esquí; 2) instalaciones y servicios; 3) entorno, y 4) promoción (ver tabla 3).

\subsection{Comunicación (C)}

La capacidad de interacción en la comunicación entre el cliente y la empresa o el destino turístico es clave a la hora de diseñar la presencia web (Marimon et al., 2010), ya que conlleva ventajas como, por ejemplo: mayor tiempo de permanencia en la web, mayor procesamiento e impacto de la información y creación de una relación con el cliente (Huertas y Marine-Roig, 2015). Dada la naturaleza intangible de los servicios turísticos y el gran uso que se hace de las redes sociales, las recomendaciones personales se convierten en un elemento muy influyente a la hora de tomar una decisión de compra (Xiang y Gretzel, 2010; Filieri y McLeay, 2014). Por tanto, es de vital importancia para las empresas y los destinos turísticos introducir aplica- 
Tabla 3. Listado de ítems para la variable información (I)

\begin{tabular}{|c|c|}
\hline Categorías & Ítems \\
\hline \multirow[t]{15}{*}{$\begin{array}{l}\text { 1. Información sobre las } \\
\text { estaciones de esquí }\end{array}$} & $\begin{array}{l}\text { I.1.1. Descripción de la estación de esquí (tipo de estación, número } \\
\text { de remontes, kilómetros esquiables, espesores de nieve, cotas, } \\
\text { etc.). }\end{array}$ \\
\hline & I.1.2. Tours virtuales. \\
\hline & I.1.3. Fotos de la estación. \\
\hline & $\begin{array}{l}\text { I.1.4. Disponibilidad de información sobre tarifas de forfaits y abonos } \\
\text { de temporada. }\end{array}$ \\
\hline & I.1.5. Comunicación de noticias y eventos. \\
\hline & I.1.6. Información acerca de la localización de la estación. \\
\hline & I.1.7. Enlaces a webs de valoración de servicios turísticos. \\
\hline & I.1.8. Estado de la estación (abierta o cerrada). \\
\hline & $\begin{array}{l}\text { I.1.9. Estado de los accesos a la estación (abiertos, cerrados, cade- } \\
\text { nas). }\end{array}$ \\
\hline & I.1.10. Parte de meteorología: actual o previsión. \\
\hline & I.1.11. Planos de pistas. \\
\hline & I.1.12. Disponibilidad de reglamento de seguridad en pistas. \\
\hline & I.1.13. Disponibilidad de reglamento del uso del forfait. \\
\hline & I.1.14. Calendario completo de la temporada. \\
\hline & $\begin{array}{l}\text { I.1.15. Diferencia respecto a la información acerca de las temporadas } \\
\text { de invierno y de verano. }\end{array}$ \\
\hline
\end{tabular}

2. Instalaciones y servicios l.2.1. Información sobre los restaurantes. de la estación de esquí

I.2.2. Información sobre la escuela de esquí.

I.2.3. Información sobre el servicio de guardería.

I.2.4. Información sobre el servicio de taquillas y guardaesquís.

I.2.5. Información sobre la tienda.

3. Entorno de la estación I.3.1. Información turística sobre la zona en la que se encuentra de esquí ubicado el establecimiento.

I.3.2. Enlaces a otros negocios relacionados (alojamientos, restaurantes, deportes de aventura, etc.).

4. Promoción

I.4.1. Promoción y anuncios publicitarios.

I.4.2. Incentivos: bonos o cupones, ofertas solo por Internet, concursos en línea.

Fuente: elaboración propia.

ciones en sus sitios web que favorezcan la retroalimentación con el cliente (Celaya, 2011) y en los cuales el turista tenga un papel activo (Bingley et al., 2010), especialmente redes sociales que se caracterizan por su inherente interactividad (Huertas y Marine-Roig, 2015). A través de esta variable constituida por tres categorías, se medirá la disponibilidad de herramientas de la web de la estación de esquí para comunicarse con el cliente (ver tabla 4). Adicionalmente, se identifica si existe una versión del sitio web en otro idioma (al menos en inglés). 
Tabla 4. Listado de ítems para la variable comunicación (C)

\begin{tabular}{|c|c|}
\hline Categorías & Ítems \\
\hline \multirow{8}{*}{$\begin{array}{l}\text { 1. Interacción con } \\
\text { los clientes }\end{array}$} & C.1.1. Correo electrónico y teléfono del establecimiento. \\
\hline & C.1.2. Posibilidad de recoger comentarios en línea de los clientes. \\
\hline & C.1.3. Mensajería instantánea. \\
\hline & C.1.4. Encuestas en línea. \\
\hline & C.1.5. Área de preguntas frecuentes. \\
\hline & C.1.6. Pueden optar por recibir boletines electrónicos. \\
\hline & C.1.7. Área de acceso restringido para clientes. \\
\hline & $\begin{array}{l}\text { C.1.8. Posibilidad de dejar votar a los clientes sobre la calidad o la satis- } \\
\text { facción sobre los servicios prestados. }\end{array}$ \\
\hline \multirow[t]{10}{*}{ 2. Recursos web 2.0} & C.2.1. Sindicación de contenidos (RSS). \\
\hline & C.2.2. Podcasting y vodcasting. \\
\hline & $\begin{array}{l}\text { C.2.3. Aplicaciones que permitan la publicación de contenidos por } \\
\text { parte del usuario. }\end{array}$ \\
\hline & $\begin{array}{l}\text { C.2.4. Posibilidad de que los clientes compartan contenido con sus ami- } \\
\text { gos (retuitear, compartir, etc.). }\end{array}$ \\
\hline & C.2.5. Enlace a Twitter (microblogueo). \\
\hline & C.2.6. Enlace al blog de la empresa. \\
\hline & $\begin{array}{l}\text { C.2.7. Enlaces a plataformas de imágenes y vídeos externos (YouTube, } \\
\text { Flickr, etc.). }\end{array}$ \\
\hline & C.2.8. Enlaces a redes sociales de la empresa (Facebook, Linkedln, etc.). \\
\hline & C.2.9. Enlace a wiki. \\
\hline & C.2.10. Otras plataformas 2.0 (Technorati, Netvibes, etc.). \\
\hline $\begin{array}{l}\text { 3. Capacidades } \\
\text { idiomáticas }\end{array}$ & C.3. Página web disponible en más de un idioma. \\
\hline
\end{tabular}

Fuente: elaboración propia.

\subsection{Comercio electrónico (CE)}

Esta dimensión hace referencia a la capacidad de distribución y comercialización de productos turísticos (Álvarez, 2014). A través de este indicador, se evaluarán los aspectos relativos a los mecanismos para la reserva, el pago y la seguridad en el pago de los servicios.

\subsection{Funciones adicionales (FA)}

Siguiendo la línea del trabajo de Álvarez (2014), se ha considerado añadir una serie de aspectos adicionales teniendo en cuenta las regulaciones sobre comercio electrónico en España, como es el caso de la protección de datos y las certificaciones de calidad. En la actualidad, la funcionalidad y la accesibilidad están alcanzando una importancia crítica para los usuarios (Buhalis y Law, 2008; Cristóbal-Fransi, 2006). Por otro lado, y teniendo en cuenta el cada vez mayor uso de la tecnología móvil, se consideró pertinente incluir en el análisis 
Tabla 5. Listado de ítems para la variable comercio electrónico (CE)

\begin{tabular}{ll}
\hline \multicolumn{1}{c}{ Categorías } & \multicolumn{1}{c}{ Ítems } \\
\hline Servicios de reserva & CE.1. Reserva en línea. \\
y pago en línea. & CE.2. Pago en línea. \\
\hline
\end{tabular}

Fuente: elaboración propia.

la existencia de una versión móvil en el sitio web de los establecimientos. Según Kaplan y Haenlein (2010) y Kim et al. (2015), los dispositivos móviles se convertirán, y ya están siendo en la actualidad, una de las principales herramientas de búsqueda de información y pago para las compras en el sector turístico.

Tal como hemos comentado anteriormente, para alcanzar el objetivo planteado, se ha optado por la evaluación del sitio web desde la perspectiva de marketing. En el procedimiento de evaluación, se procedió a la identificación de los contenidos y de los servicios que se ofrecen en línea. El análisis se ha llevado a cabo mediante la identificación de una serie de posibles contenidos informativos y servicios interactivos que se consideran útiles o atractivos para un usuario de un sitio web de turismo (Álvarez, 2014; Escobar y Carvajal, 2013; Law et al., 2010; Lee y Morrison, 2010). Cada uno de los ítems se escogió a partir de la revisión de la literatura, añadiendo nuevos elementos para adaptarlos al caso de las estaciones de esquí.

Para llevar a cabo el trabajo de campo, se elaboró una plantilla siguiendo el modelo propuesto anteriormente, en la cual se identificaron los diferentes aspectos que se iban a tomar en consideración a partir de la revisión de la literatura sobre el tema. A fin de conocer en qué situación se encontraban las webs en lo relativo a la presencia en línea, al nivel de información y de interacción en Internet, se decidió usar la técnica del análisis de contenido con perspectiva cuantitativa (Álvarez, 2014; Chiou et al., 2011; Lee y Morrison, 2010), utilizando para ello una plantilla con 52 indicadores para analizar en relación con las dimensiones de información, comunicación, comercio electrónico y funciones adicionales para cada uno de los sitios web de las estaciones de esquí, siguiendo el modelo propuesto anteriormente.

El análisis se centró en los sitios web de las estaciones de esquí de España y Andorra. Para alcanzar los objetivos propuestos, se analizaron los sitios web

Tabla 6. Listado de ítems para la variable funciones adicionales (FA)

\begin{tabular}{ll}
\hline \multicolumn{1}{c}{ Categorías } & \multicolumn{1}{c}{ ĺtems } \\
\hline 1. Seguridad de la información & FA.1. Política de privacidad o aviso legal. \\
\hline 2. Certificaciones & FA.2.1. Certificaciones de calidad ISO 9000. \\
& FA.2.2. Certificación Q de Calidad Turística. \\
& FA.2.3. Certificaciones de medio ambiente (ISO 14000). \\
& FA.2.4. Otras certificaciones (ISO 27000, OSHAS 18000). \\
\hline 3. Versión móvil & FA.3.1. Poseer enlace web a versión móvil del sitio web. \\
& FA.3.2. Disponibilidad de la aplicción de la estación.
\end{tabular}

Fuente: elaboración propia. 
correspondientes a la totalidad de las estaciones de esquí de montaña asociadas a ATUDEM, estaciones del Principado de Andorra, incluyendo estaciones de esquí de fondo de pequeño tamaño: 31 alpinas, 21 nórdicas y 1 cubierta. El estudio se extiende, a su vez, a los dominios esquiables de Andorra, debido a la gran tradición de práctica del deporte blanco que posee el principado de Andorra y a la gran afluencia de esquiadores de nuestro país. En total, han sido 53 sitios web analizados. El trabajo de campo fue realizado durante el periodo comprendido entre enero y abril de 2015.

\section{Resultados}

Para identificar la presencia de cada uno de los elementos, además de facilitar el análisis y las comparaciones entre las tipologías de estaciones, los resultados expuestos representan el porcentaje de establecimientos que utiliza cada herramienta según el tipo de estación al que pertenece.

\subsection{Dimensión información}

La primera de las dimensiones analiza los mecanismos establecidos por las estaciones de esquí para informar acerca de sus productos y servicios, así como otras informaciones de interés turístico para la zona. Lo primero que se puede señalar es la gran diferencia de presencia de contenidos en función de la tipología de la estación, siendo las de esquí alpino las que muestran un mayor desarrollo. Como se puede observar en la figura 2, los contenidos relativos a la información sobre las estaciones de esquí (I.1) y sobre sus instalaciones y servicios (I.2) están muy bien representados, sobre todo en las estaciones de esquí alpino, como hemos comentado anteriormente. Por tanto, podemos afirmar que, en cuanto a la difusión de la información, las estaciones de esquí cumplen con las condiciones básicas para que el cliente pueda informarse a la hora de escoger su destino de turismo de nieve.

En cuanto a los aspectos negativos, es de destacar la escasa existencia de información sobre servicios de taquillas y guardaesquís (I.2.5) o de aspectos relacionados con la web 2.0, como las visitas virtuales (I.1.2) o la disponibilidad de enlaces a sitios web de valoraciones (I.1.7). Otro aspecto a mejorar es la diferenciación de la información para la temporada de invierno y la de verano (I.1.15). La gestión de la presencia web de las estaciones de esquí debería reforzar estos atributos de la dimensión de información, ya que son clave y pueden constituir elementos determinantes en la decisión del destino de los esquiadores a través de la web.

\subsection{Dimensión de comunicación}

La dimensión de comunicación está formada por aquellas herramientas que favorecen la interacción con el cliente a través del sitio web y de la web 2.0. También contempla la capacidad de ofrecer su contenido en varios idiomas. 
Figura 2. Indicadores de información por tipología de estación de esquí

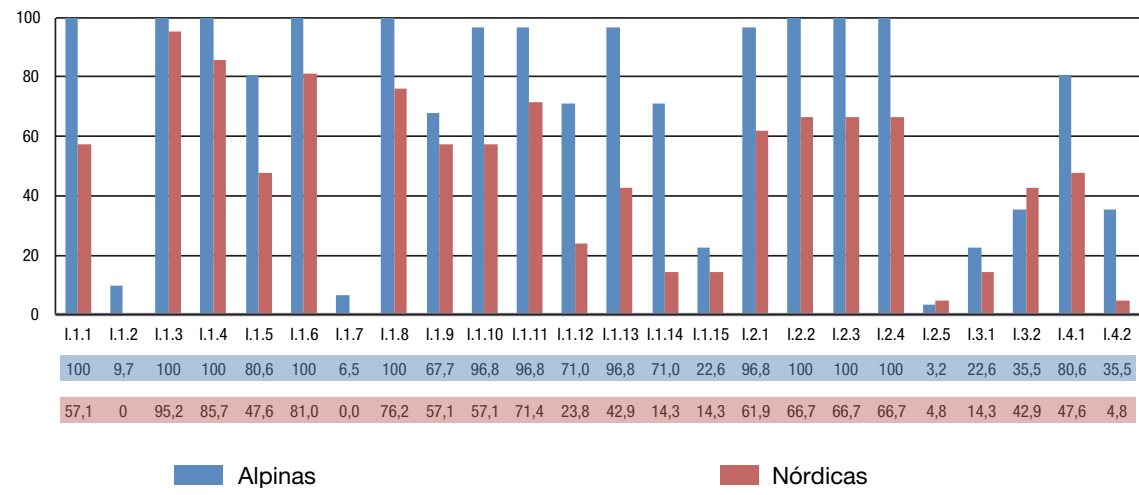

Fuente: elaboración propia.

Tal como se puede observar en la figura 3, los ítems relacionados con la interactividad presentan unos resultados significativamente inferiores a la dimensión anterior. En general, los establecimientos apenas utilizan la web para establecer el diálogo con los usuarios a través de la misma. Como se puede apreciar, las vías de información más habituales para ponerse en contacto con los usuarios son las tradicionales, es decir, el teléfono y el correo electrónico (C.1.1), seguidas de formularios donde recoger los comentarios de los clientes (C.1.2). En menor medida, se utilizan las preguntas frecuentes (C.1.5) o las revistas editadas por la propia empresa (C.1.6). Por otro lado, también se tiene que destacar que, en ninguno de los sitios web

Figura 3. Indicadores de interactividad por tipología de estación de esquí

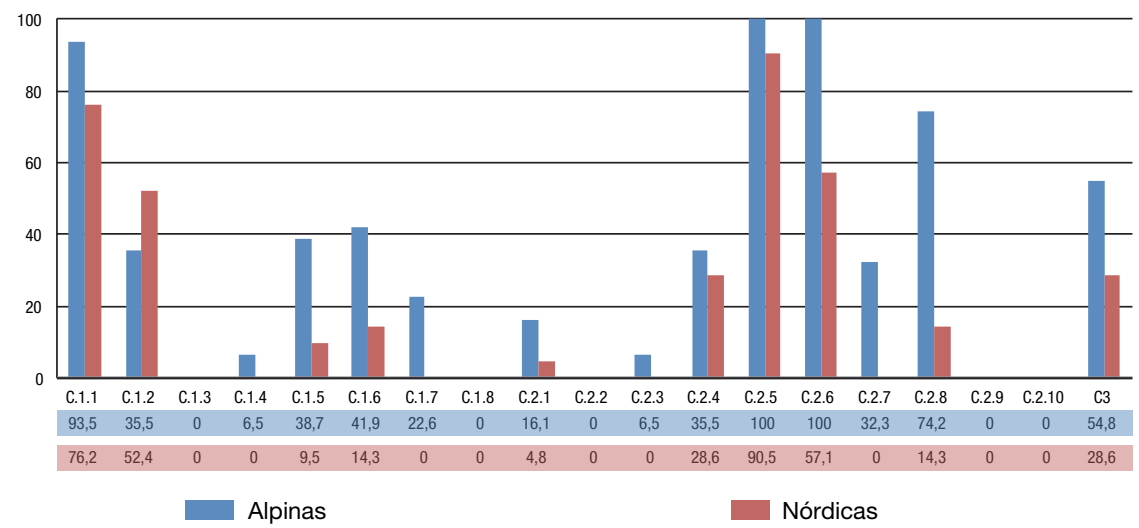

Fuente: elaboración propia. 
analizados, se encuentran instrumentos de mensajería instantánea (C.1.3) o la posibilidad de que los clientes voten sobre la calidad o la satisfacción de los servicios prestados.

Respecto a la interactividad a través de la web 2.0, los resultados son significativamente superiores a la variable de interacción a través de la web, aunque hay una importante diferencia en función de la tipología de la estación de esquí, siempre a favor de las alpinas. La gran mayoría de los sitios web analizados disponen de enlaces a la cuenta de Twitter, enlaces a sus propios blogs (C.2.6) y a otras redes sociales, como Facebook o Linkedin (C.2.8). En menor medida, encontramos enlaces a plataformas de imágenes o vídeos externos tipo YouTube o Flickr (C.2.8). La sindicación de contenidos (C.2.1) o las aplicaciones que permiten la publicación de contenidos por parte del usuario (C.2.3) tienen una presencia mucho más limitada (un 16,1\% en el mejor de los casos).

En cuanto a la presentación de los sitios web en diferentes idiomas, el número de estaciones que poseen una versión en al menos otro idioma es de un 44,2\%, siendo las estaciones alpinas las que más destacan en ese aspecto, con un 54,8\% del total. Esta situación reviste una mayor importancia si se analiza que, según un informe de FRONTUR (2015), los principales países emisores de turistas a España en el 2011 fueron el Reino Unido, Alemania y Francia, que congregaron conjuntamente en torno al 59,2\% de los turistas recibidos (IET, 2015).

\subsection{Dimensión de comercio electrónico}

La dimensión de comercio electrónico caracteriza los mecanismos de pago y reserva ofrecidos por parte de las estaciones de esquí para que los usuarios puedan acceder a sus productos y servicios a través de la web oficial de la estación. El análisis de la figura 4 permite ver que, a pesar de los avances en materia de comercio electrónico a nivel nacional, en este tipo de instalaciones de turismo de nieve y de montaña, aún existen niveles bajos de implementación de mecanismos en línea de reserva y pago. Los peores indicadores se encuentran reflejados en las estaciones de esquí nórdico, ya que solo el $28,6 \%$ de ellas posee la opción de reserva en línea (CE.1) y la opción de pago en línea (CE.2). Las estaciones de esquí alpino, por su parte, ofrecen un 58,1\% la opción de reserva en línea (CE.1), mientras que el 64,5\% brinda la opción de pago en línea (CE.2).

\subsection{Dimensión de funciones adicionales (FA)}

En la última de las dimensiones, se incluyen aquellos aspectos generales que se considera pueden ser relevantes para un sitio web según el contexto actual. El mismo se divide en tres aspectos fundamentales a evaluar (tabla 3 ).

La última de las dimensiones a evaluar muestra un comportamiento más o menos similar al resto. Respecto a la política de privacidad o aviso legal (FA.1), 
Figura 4. Indicadores sobre comercio electrónico por tipología de estación de esquí

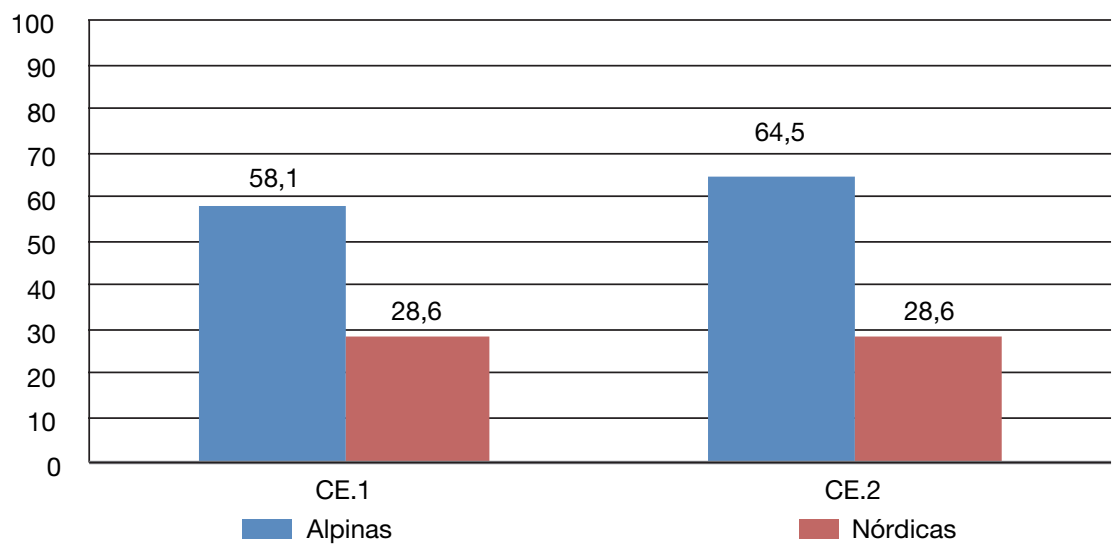

Fuente: elaboración propia.

solo el $57,7 \%$ de las estaciones de esquí hace alusión a dicho indicador. En el caso de las estaciones de esquí nórdico, se trata únicamente del 23,8\%. Es una cifra significativamente baja, sobre todo si se compara con las estaciones alpinas, que se eleva al 80,6\%. En cuanto a las certificaciones de calidad, todavía se observan unos resultados más pobres, siendo únicamente las estaciones de esquí alpino las que muestran que disponen de certificaciones de $\mathrm{Q}$ de Calidad Turística (FA.2.2) u otras certificaciones (FA.2.4).

Por último, respecto a la disponibilidad de una versión móvil (F3), se observa que, del total de sitios web analizados, el 59,6\% posee enlaces a la versión móvil del sitio web (FA.3.1), y un 26,9\% dispone de una aplicación móvil (FA.3.2). Este resultado puede resultar especialmente significativo si se tiene en cuenta que, según un estudio de mercado de aplicaciones turísticas llevado a cabo por Segittur (2013), dos de cada tres viajeros tienden a comprar, buscar y reservar sus actividades turísticas a través del móvil y tres de cada cuatro viajeros habituales usan el teléfono inteligente durante su estancia en el destino. Siguiendo esta línea, webs consolidados en el mercado, como es el caso de Facebook y YouTube, ya han implementado la versión móvil de sus sitios web, consiguiendo resultados positivos (Cortimiglia et al., 2011). En este entorno, acceder a este importante nicho de mercado a través de los terminales móviles puede convertirse en una importante ventaja competitiva para las empresas del sector turístico (Álvarez et al., 2013).

Del análisis de estos cuatro indicadores, se desprende que la gran mayoría de las estaciones de esquí de España y Andorra tiene una presencia en línea básica y frecuentemente estática, sobre todo si nos centramos en las estaciones de esquí nórdico. Estos resultados son congruentes con otros estudios en el ámbito español, que indican que los sitios webs son escaparates estáticos de productos y servicios donde no se aprovecha su capacidad dinámica y colabora- 
Figura 5. Indicadores de funciones adicionales por tipología de estación de esquí

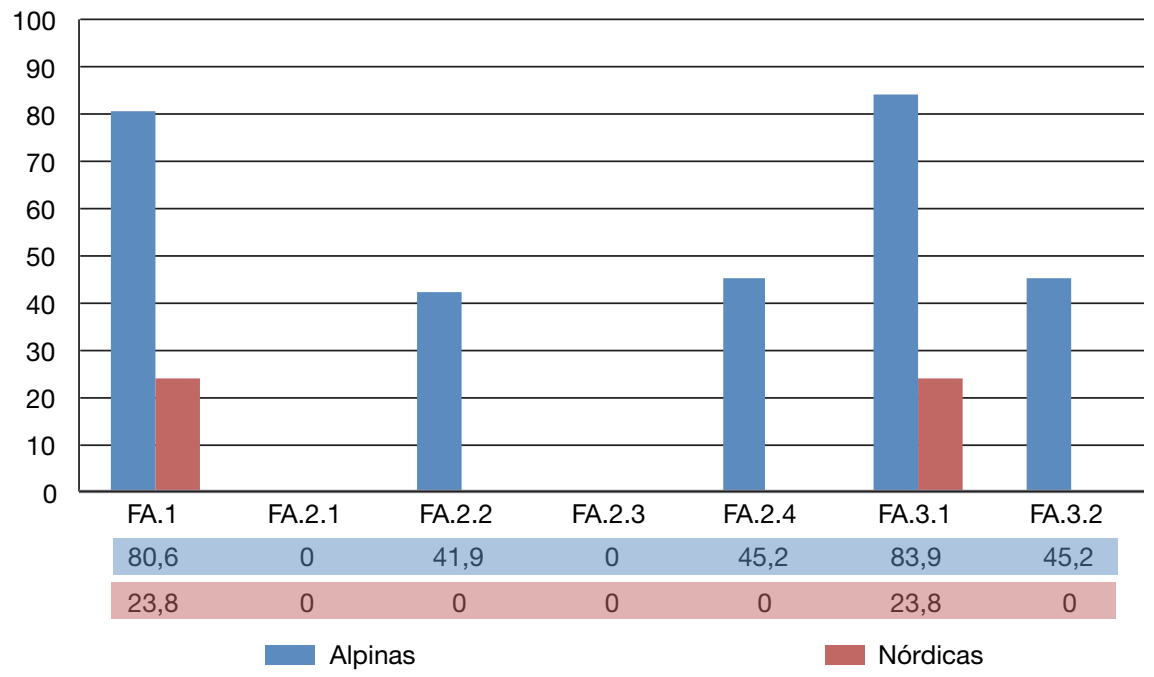

Fuente: elaboración propia.

tiva, que fomenta una relación bilateral sobre los contenidos entre sus usuarios (Álvarez, 2014; Celaya, 2011). En un estudio realizado por Escobar y Carvajal (2013) sobre los sitios web de los hoteles en España, se determinaba que, en general, estas webs turísticas no habían adoptado estrategias que favorecieran la interacción con los clientes ni que incitaran a la recomendación de sus productos o servicios en la red.

\subsection{Resultados por ámbito geográfico}

Si estudiamos los resultados en función del área geográfica, podemos encontrar diferencias significativas. Tal y como se puede observar en la figura 6, el número de visitantes por cordillera es mucho más elevado en el Pirineo, con prácticamente un $60 \%$ del total de los esquiadores de toda España, seguido del Sistema Penibético, que congrega el 20\% de los esquiadores.

A nivel europeo, podemos observar, en la figura 7, como hay un grupo destacado de países formado por Francia y Austria, con más de 50 millones de visitantes por temporada, seguido de Italia y Suiza, con 30 y 22 millones respectivamente. Finalmente, encontramos un tercer grupo donde se ubicaría España, con unos 5 millones de visitantes. Andorra le seguiría con unos 2 millones de esquiadores.

Las estaciones de esquí que cumplen con más indicadores de las diferentes dimensiones de información, comunicación, comercio electrónico y funciones adicionales del modelo propuesto, y, por tanto, las que podemos considerar que 
Figura 6. Evolución de visitantes por cordillera y por temporada

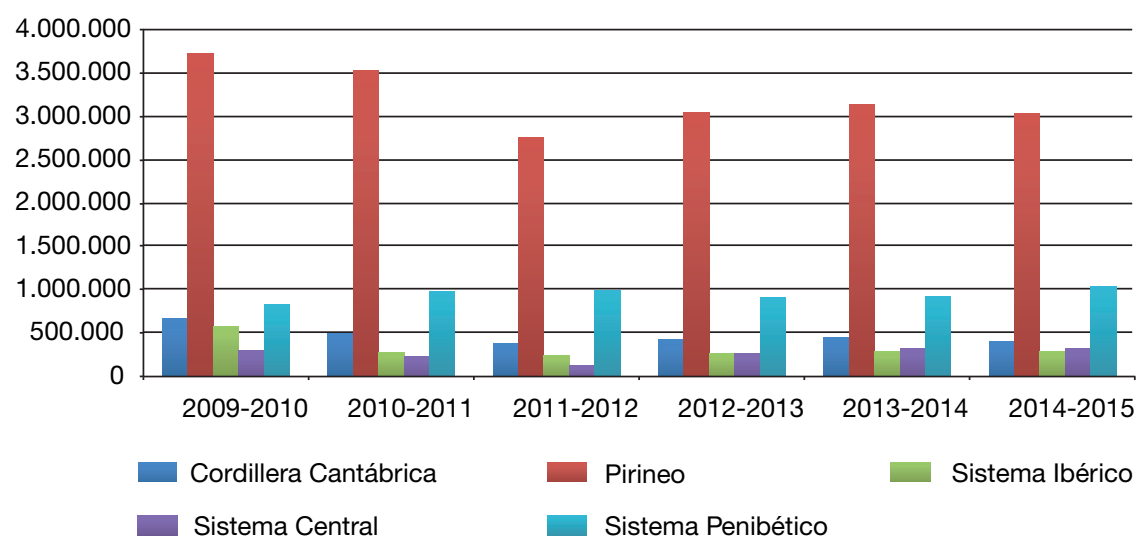

Fuente: elaboración propia a partir de ATUDEM (2015).

muestran un nivel más óptimo de presencia en Internet, son, en primera posición y a un mismo nivel, Baqueira-Beret, Vall de Núria, Astún, Sierra Nevada y GrandValira; seguidos de La Molina y Vallnord; en tercera posición, encontramos Vallter 2000 y Valgrande-Pajares, y, en cuarta, Espot Esquí y Port Ainé.

Por cordilleras, las pistas de esquí de Andorra son las que cumplen, de media, con más indicadores, seguidas de las estaciones de la Cordillera Cantábrica, del Sistema Ibérico y del Pirineo catalán, tal y como se puede observar

Figura 7. Evolución de visitantes por países y por temporada

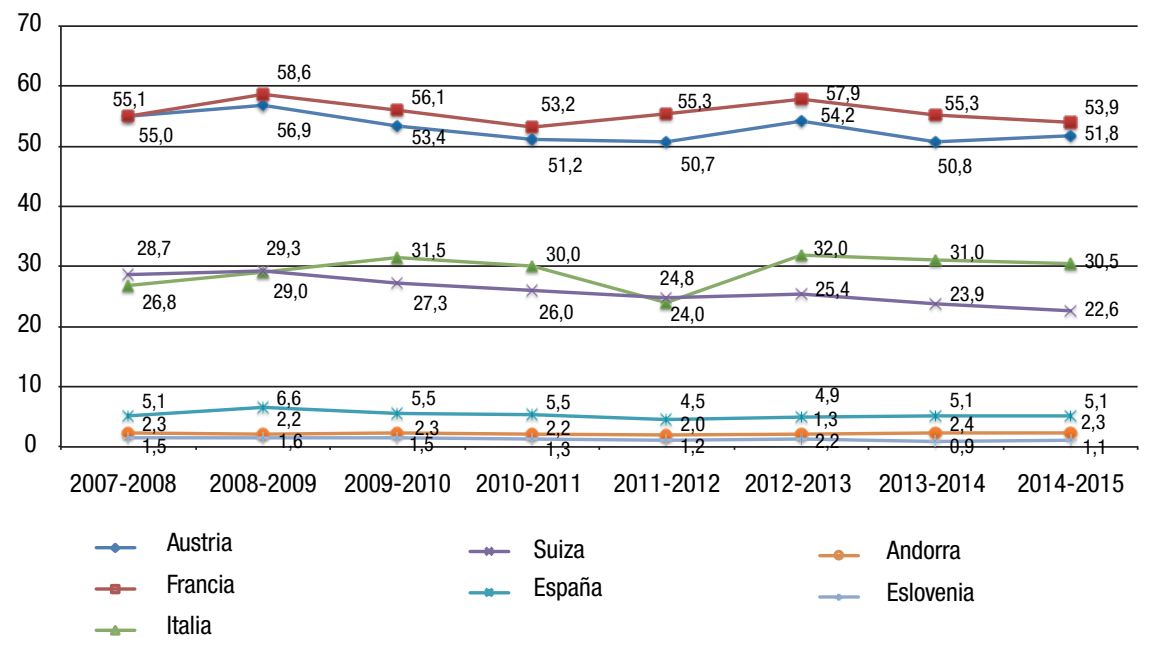

Fuente: elaboración propia a partir de ATUDEM (2015). 
Tabla 7. Análisis de contenido web medio por región y por tipo de estación

\begin{tabular}{lccc}
\hline Región & Total & Alpino & Nórdico \\
\hline Pirineo catalán & 25,53 & 30,40 & 15,80 \\
Pirineo aragonés & 18,00 & 29,40 & 10,88 \\
Sistema lbérico & 27,00 & 27,00 & - \\
Sistema Central & 23,80 & 24,50 & 21,00 \\
Cordillera Cantábrica & 27,17 & 27,17 & - \\
Sistema Penibético & 25,00 & 35,00 & 15,00 \\
Pistas de esquí de Andorra & 29,33 & 39,50 & 19,00 \\
\hline
\end{tabular}

Fuente: elaboración propia.

en la tabla 7. En referencia a las estaciones de esquí alpino, las andorranas son también las que dominan la clasificación, seguidas de las del Sistema Penibético y del Pirineo catalán. Para las pistas de esquí nórdico, las estaciones del Sistema Central son las que cumplen con más indicadores del modelo propuesto, seguido de las pistas andorranas.

\section{Conclusiones}

El objetivo principal de este trabajo ha sido estudiar la eficacia de los sitios web de las estaciones de esquí de España y Andorra, analizando si el contenido de estas páginas web facilita una comunicación interactiva y proponiendo un modelo comprensible de análisis que pueda ser útil, no solo para el estudio de la comunicación web de estaciones de esquí, sino también para otros tipos de empresas turísticas y de servicios. Este objetivo se ha desarrollado partiendo del planteamiento teórico de los conceptos de turismo de nieve y de montaña y de tecnologías de la información y de la comunicación en el diseño de sitios web, para, posteriormente, aplicar un análisis de contenido siguiendo el modelo propuesto.

Esta investigación ha identificado una serie de resultados para cada uno de los aspectos analizados: información, comunicación, comercio electrónico y funciones adicionales. En primer lugar, se ha podido observar que los sitios web de este tipo de instalaciones turísticas de montaña ofrecen una importante cantidad de información.

A pesar de la falta de datos sobre algunos servicios ofrecidos por las empresas o acerca del territorio, podemos afirmar que las estaciones de esquí cumplen con las condiciones básicas para que el cliente pueda informarse a la hora de escoger su destino de turismo de nieve. En segundo lugar, y centrándonos en la dimensión de comunicación, se ha constatado que las estaciones de esquí analizadas utilizan principalmente los medios tradicionales de comunicación con sus usuarios, como, por ejemplo, el correo electrónico o bien el teléfono, aunque prestando interés a recursos más interactivos, como es la presencia en redes sociales, en blogs o en plataformas de intercambio de imágenes o de vídeo. En tercer lugar, y respecto a la dimensión de comercio electrónico, en 
las estaciones de esquí analizadas, se puede afirmar que aún existen niveles bajos de implementación de mecanismos en línea de reserva y pago y que aún queda margen de mejora.

Finalmente, en cuanto a la dimensión de funciones adicionales, las estaciones de esquí alpinas sí que muestran información sobre la política de privacidad o bien las certificaciones de calidad de que disponen, pero las estaciones de esquí nórdicas muestran unos datos significativamente inferiores, por lo que todavía queda mucho recorrido por realizar. En general, del total de páginas web analizadas, destacan las de las estaciones de esquí alpino, por ser las que presentan una mayor orientación al mercado y las que incorporan en mayor grado elementos de la web 2.0.

Estos resultados aportan información sobre algunas características positivas de las estaciones de esquí, aunque existen áreas que podrían mejorarse, ya que estas instalaciones turísticas no han alcanzado un nivel óptimo en su objetivo de mantener una comunicación con un elevado grado de interacción con su público objetivo. En este sentido, los sitios web analizados tienen una efectividad media, ya que no incorporan todos los ítems necesarios para proporcionar un nivel suficiente de información y una adecuada comunicación interactiva con su usuario. Este hecho podría deberse a que la inversión destinada al diseño de estas aplicaciones para aprovechar las oportunidades de mercado, como es la generación de relaciones tanto con sus clientes como con nuevos usuarios mediante Internet, no es óptima.

Ante las reestructuraciones y las transformaciones que muchas estaciones de esquí se ven obligadas a hacer por el descenso de las actividades de invierno ligado al cambio climático, es posible que aquellas no consideren el desarrollo de su web y, especialmente, de sus posibilidades interactivas 2.0 como una inversión prioritaria. Estas carencias pueden estar ligadas también a la mentalidad de gestión y al hecho de que las organizaciones consideren que el público objetivo no requiere este tipo de información o que no es necesario desarrollar relaciones bilaterales ni interactividad con los clientes para el buen funcionamiento del negocio.

Aunque, a través de los resultados de la presente investigación, se ha comprobado que, actualmente, las estaciones de esquí son conscientes de la importancia de estar presentes en la red, ya que todas ellas tienen acceso a Internet y disponen de sitio web, su mera presencia no es suficiente, por lo que es necesario que estas organizaciones vayan más allá de la presencia tradicional, favorezcan la interacción y la colaboración en línea, así como la conectividad y la posibilidad de generar y compartir contenidos y conocimientos por parte de los usuarios utilizando técnicas de la web 2.0.

Por tanto, las variables propuestas en el modelo de análisis podrían ayudar a diagnosticar y a mejorar la eficacia de la comunicación en las estaciones de esquí con sus usuarios y sus clientes potenciales, ya que marcan las pautas para el diseño de sus sitios web.

Fruto de los resultados obtenidos, se pueden transformar los aspectos tratados en recomendaciones que sugieran posibles acciones de futuro que ayuden a transformar a las estaciones de esquí en organizaciones con una fuerte orien- 
tación hacia el cliente. Las estaciones de esquí deben incorporar, en sus sitios web, una serie de elementos que proporcionen una mayor conexión con los usuarios que accedan a la misma. Estas empresas tienen que intentar generar una importante retroacción entre ellas y sus visitantes, lo que contribuirá a mejorar la gestión de la organización. También es recomendable incorporar más contenido informativo, tanto de los servicios de la estación como de los recursos turísticos del entorno. Esto haría que el contenido del sitio web sea apropiado para las exigencias de su público objetivo.

Finalmente, se puede afirmar que la información derivada de la presente investigación representa un valor añadido, tanto para las estrategias de marketing en general como para el desarrollo de la presencia en línea de las estaciones de esquí. Los gestores de estas organizaciones deben tener en cuenta las dimensiones analizadas en este trabajo, para poder interactuar de una manera más óptima con su público objetivo. En definitiva, se pretende conseguir que Internet se convierta en un canal para la globalización en el sector del turismo de nieve mediante un eficaz sistema B2C, creando mercados virtuales innovadores entre las estaciones de esquí y los usuarios tanto reales como potenciales.

Respecto a las implicaciones en la gestión de este tipo de empresas turísticas, se recomienda a sus gestores que presten atención al sitio web para mejorar la actitud de sus consumidores, ya que una buena presencia en línea tendrá un impacto positivo en la imagen de la organización. Para ello, a la hora de diseñar la web corporativa de la estación de esquí, se tienen que seguir una serie de pautas e incluir un conjunto de elementos fundamentales alrededor de las cuatro dimensiones propuestas: información, comunicación, comercio electrónico y funciones adicionales. Una presencia eficaz en Internet permitirá alcanzar mejores resultados, ya sea en número de visitas, ya en número de reservas realizadas.

Por otra parte, se ha demostrado que el modelo propuesto de análisis de contenido web, basado en las dimensiones información, comunicación, comercio electrónico y funciones adicionales ha sido útil y eficaz para el análisis de la comunicación web de las estaciones de esquí, y puede ser de utilidad para los gestores de las mismas o para otros gestores de empresas turísticas que deseen evaluar hasta qué punto están siendo aprovechadas las potencialidades que brindan las TIC en la comunicación a través de su página web.

Respecto a las limitaciones de este estudio, se puede señalar el hecho de que la investigación mostrada ha analizado la presencia en Internet de las estaciones de esquí a través de unos ítems obtenidos a partir de la revisión de la literatura, pero sin tener en cuenta otros factores, como, por ejemplo, el tamaño de la empresa, entre otros. Otra limitación es el carácter transversal de la investigación, que no permite estudiar la evolución de los sitios web analizados. Para solucionar esta limitación, y como futura línea de investigación, se podría diseñar un estudio de carácter transversal para analizar el desarrollo de la presencia en línea de este sector turístico a lo largo del tiempo.

Como futura línea de investigación basada en los resultados presentados, se propone ampliar el número de estaciones de esquí ubicadas en otros países para 
disponer de más datos y poder comparar resultados. Además, se podrían realizar entrevistas personales a los directivos de estas instalaciones o administrar un cuestionario a usuarios de dichas estaciones para determinar los elementos a evaluar en un sitio web y estudiar las causas para las carencias informativas e interactivas de estos sitios. Finalmente, se puede diseñar una investigación donde se contemple el tamaño de la estación de esquí. En el presente estudio, se ha tenido en cuenta la totalidad de las estaciones sin realizar ninguna distinción, y podría ser interesante llevar a cabo un análisis comparativo para analizar las diferencias entre estaciones de montaña grandes y pequeñas.

\section{Agradecimientos}

Los autores agradecen a la Generalitat de Catalunya la acreditación concedida como Grupo Emergente de Investigación GRTESC (2014 SGR 82). A su vez, agradecen a la Universidad de Lleida la ayuda concedida dentro del marco del Programa de Promoción de la Investigación de la UdL, convocatoria 2014.

\section{Referencias bibliográficas}

Atudem (2015). Información sobre la temporada de esqui 2014-15. <http://www.atudem.es/20151001/Temporada-Esqui-2014-15.aspx> [en línea] [Consulta: 15 julio 2015].

- (2017). Guía oficial de estaciones de esqui 2017. <http://www.atudem.es/20151023/ Guia-estaciones.aspx> [en línea] [Consulta: 28 febrero 2017].

Álvarez, Y. (2014). La orientación al mercado en el sector turístico con el uso de las herramientas de la web social, efectos en los resultados empresariales [en línea]. Santander: Universidad de Cantabria. Tesis doctoral. <http://hdl.handle.net/10902/5018> [Consulta: 15 julio 2015].

Álvarez, Y.; Pérez-González, D. y Solana, P. (2013). "Contribución de la web 2.0 al desempeño organizacional en las empresas del sector turismo». Puente: Revista Científica Universidad Pontificia Bolivariana Seccional Bucaramanga, 17 (2), 7-13.

Baggio, R.; Mottironi, C. y Corigliano, M. (2011). «Technological aspects of public tourism communication in Italy». Journal of Hospitality and Tourism Technology [en línea], 2 (2), 105-119. <http://dx.doi.org/10.1108/17579881111154227>

Baloglu, S. y Pekcan, Y. (2006). «The website design and internet site marketing practices of upscale and luxury hotels in Turkey». Tourism Management [en línea], 27 (1), 171-176.

<http://dx.doi.org/10.1016/j.tourman.2004.07.003>

Bingley, S.; Burgess, S.; Sellitto, C.; Cox, C. y Buultjens, J. (2010). «A classification scheme for analyzing web 2.0 tourism websites». Journal of Electronic Commerce Research, 11 (4), 281-298.

Buhalis, D. (2000). «Tourism and Information technologies: Past, present and future». Tourism Recreation Research [en línea], 25 (1), 41-58. <http://dx.doi.org/10.1080/02508281.2000.11014899> 
Buhalis, D. y Law, R. (2008). "Progress in information technology and tourism management: 20 years on and 10 years after the Internet - The state of eTourism research». Tourism Management [en línea], 29 (4), 609-623. <http://dx.doi.org/10.1016/j.tourman.2008.01.005>

Burgess, L. y Cooper, J. (1998). «The Status of Internet Commerce in the Manufacturing Industry in Australia: A survey of Metal Fabrication Industries». Proceedings of the Second CollECTeR Conference on Electronic Commerce, 65-73. Sydney.

Calbó, J.; Sánchez-Lorenzo, A.; Barrera, A. y Cunillera, J. (2012). «Climate change projections for Catalonia (NE Iberian Peninsula). Part II: Integrating several methodologies». Journal of Mediterranean Meteorology \& Climatology (Tethys) [en línea] (9), 13-24. <http://dx.doi.org/10.3369/tethys.2012.9.02>

Cantoni, L.; Fans, M.; Inversini, A. y Passini, V. (2011). «Hotel websites and booking engines: A challenging relationship». En: LAw, R.; Fuchs, M. y RicCI, F. (eds.). Information and Communication Technologies in Tourism 2011 [en línea]. Viena: Springer, 241-252. <http://dx.doi.org/10.1007/978-3-7091-0503-0_20>

Celaya, J. (2011). La empresa en la web 2.0. Barcelona: Gestión 2000.

Chang, H.H. y Chuang, S.S. (2011). "Social capital and individual motivations on knowledge sharing: Participant involvement as a moderator». Information \& Management [en línea], 48 (1), 9-18. <http://dx.doi.org/10.1016/j.im.2010.11.001>

Chiou, W.C.; Lin, C.C. y Perng, C. (2010). "A strategic framework for website evaluation based on a review of the literature from 1995-2006». Information and Management [en línea], 47 (5), 282-290.

<http://dx.doi.org/10.1016/j.im.2010.06.002>

- (2011). "A strategic website evaluation of online travel agencies». Tourism Management [en línea], 32 (6), 1463-1473. <http://dx.doi.org/10.1016/j.tourman.2010.12.007>

Chung, J.Y. y Buhalis, D. (2008). «Information needs in Online Social Networks». Information Technology Tourism [en línea], 10 (4), 267-281. <http://dx.doi.org/10.3727/109830508788403123>

Chung, T. y Law, R. (2003). «Developing a performance indicator for hotel websites». International Journal of Hospitality Management [en línea], 22 (1), 119-125. <http://dx.doi.org/10.1016/S0278-4319(02)00076-2>

Cortimiglia, M.N.; Ghezzi, A. y Renga, F. (2011). «Social applications: Revenue models, delivery channels, and critical success factors - an exploratory study and evidence from the Spanish-speaking market». Journal of Theoretical and Applied Electronic Commerce Research [en línea], 6 (2), 108-122.

Cristóbal-Fransi, E. (2006). «El merchandising en el establecimiento virtual: Una aproximación al diseño y la usabilidad». Revista Científica Esic Market, 123, $115-164$.

Cristóbal-Fransi, E.; Daries-Ramón, N. y Martín-Fuentes, E. (2013). «El turismo y el comercio electrónico en España: Un estudio del consumidor y de la empresa turística». Revista de Estudios Turísticos, 195, 79-99.

Davidson, R. (2007). «Five year longitudinal study of Australian winery websites». Proceedings of the 13th Asia Pacific Management Conference. Melbourne, Australia, 1429-1437. 
Dijkmans, C.; Kerkhof, P. y Beukeboom, C.J. (2015). «A stage to engage: Social media use and corporate reputation». Tourism Management [en línea], 47, 58-67. <http://dx.doi.org/10.1016/j.tourman.2014.09.005>

DiPietro, R.B. y WAng, Y.R. (2010). «Key issues for ICT applications: Impacts and implications for hospitality operations». Worldwide Hospitality and Tourism Themes [en línea], 2 (1), 49-67.

<http://dx.doi.org/10.1108/17554211011012595>

Escobar, T. y Carvajal, E. (2013). «An evaluation of Spanish hotel websites: Informational vs. relational strategies» [en línea]. International Journal of Hospitality Management, 33, 228-239.

<http://dx.doi.org/10.1016/j.ijhm.2012.08.008>

Esteban, A. (1995). "Los nuevos desarrollos turísticos en España y su efecto en la recuperación y/o promoción económica». Papers de Turisme, 17, 33-44.

FALK, M. (2009). "Are multi-resort ski conglomerates more efficient?». Managerial and Decision Economics [en línea], 30, 529-538.

$<$ http://dx.doi.org/10.1002/mde.1470>

- (2010). «A dynamic panel data analysis of snow depth and winter tourism». Tourism Management [en línea], 31, 912-924. <http://dx.doi.org/10.1016/j.tourman.2009.11.010>

Filieri, R. y McLeay, F. (2014). «E-WOM and accommodation: An analysis of the factors that influence travelers' adoption of information from online reviews». Journal of Travel Research [en línea], 53 (1), 44-57. <http://dx.doi.org/10.1177/0047287513481274>

Frontur (2015). Entradas de turistas según vía de acceso [en línea], <http://www.iet. tourspain.es> [consulta: 15 de julio de 2015].

García AbAD, A. (2012). «Estaciones de esquí, turismo y entorno rural de montaña: Claves para una regulación de las estaciones de esquí ante el cambio climático». Acciones e Investigaciones Sociales, 31, 91-135.

García-Lastra, O. y Escalera, G. (2008). «El uso de los sitios web en las Estaciones de Esquí y Montaña en España y Andorra». VII Congreso Turismo y Tecnologías de la Información y las Comunicaciones. TuriTec, 1-18.

Gerbaux, F. y Marcelpoil, E. (2006). «Gouvernance des stations de montagne en France: Les spécificités du partenariat public-privé». La revue de géographie alpine, 94 (1), 9-19.

Gonçalves, O. (2013). «Efficiency and productivity of French ski resorts». Tourism Management [en línea], 36. 650-657. <http://dx.doi.org/10.1016/j.tourman.2012.06.008>

González, Ó.R.; Bañegil, T.M. y Buenadicha, M. (2013). «El índice cuantitativo de calidad web como instrumento objetivo de medición de la calidad de sitios web corporativos». Investigaciones Europeas de Dirección y Economía de la Empresa [en línea], 19 (1), 16-30. <http://dx.doi.org/10.1016/j.iedee.2012.07.004>

Heinze, N. y Hu, Q. (2006). "The evolution of corporate web presence: A longitudinal study of large American companies». International Journal of Information Management [en línea], 26 (4), 313-325. <http://dx.doi.org/10.1016/j.ijinfomgt.2006.03.008>

HJalager, A. (2010). "A review of innovation research in tourism». Tourism Management [en línea], 31 (1), 1-12. <http://dx.doi.org/10.1016/j.tourman.2009.08.012> 
Huertas, A. y Marine-Roig, E. (2015). «Destination brand communication through the social media: What contents trigger most reactions of users?». En: TussYADIAH, I. e Inversini, A. (eds.). Information and Communication Technologies in Tourism 2015. Viena: Springer, 295-308. <http://dx.doi.org/10.1007/978-3-319-14343-9_22>

IET (2015). Balance del Turismo: año 2014: Resultados de la actividad turística en Espa$\tilde{n} a$ [en línea]. Madrid: Instituto de Turismo de España. <http://www.iet.tourspain. es/> [Consulta: 15 julio 2015].

JACOBSEN, J.K.S. y MunAR, A.M. (2012). «Tourist information search and destination choice in a digital age». Tourism Management Perspectives [en línea], 1, 39-47. <http://dx.doi.org/10.1016/j.tmp.2011.12.005>

Kaplan, A.M. y Haenlein, M. (2010). "Users of the world, unite!: The challenges and opportunities of social media». Business Horizons [en línea], 53 (1), 59-68. <http://dx.doi.org/10.1016/j.bushor.2009.09.003>

Kim, H. y Fesenmaier, D.R. (2008). «Persuasive design of destination web sites: An analysis of first impression». Journal of Travel Research [en línea], 47, 3-13. <http://dx.doi.org/10.1177/0047287507312405>

Kim, M.J.; Chung, N.; Lee, C. y Preis, M.W. (2015). "Motivations and use context in mobile tourism shopping: Applying contingency and task-technology fit theories». International Journal of Tourism Research [en línea], 17 (1), 13-24. <http://dx.doi.org/10.1002/jtr.1957>

Lasanta Martínez, T. (2010). "El turismo de nieve como estrategia de desarrollo en el Pirineo aragonés». Cuadernos de Investigación Geográfica, 36, 145-163.

LAw, R. y BAI, B. (2008). "How do the preferences of online buyers and browsers differ on the design and content of travel websites?». International Journal of Contemporary Hospitality Management [en línea], 20 (4), 388-400.

<http://dx.doi.org/10.1108/09596110810873507>

Law, R.; QI, S. y Buhalis, D. (2010). «Progress in tourism management: A review of website evaluation in tourism research». Tourism Management [en línea], 31 (3), 297-313. <http://dx.doi.org/10.1016/j.tourman.2009.11.007>

Lee, J.K. y Morrison, A.M. (2010). "A comparative study of web site performance». Journal of Hospitality and Tourism Technology [en línea], 1 (1), 50-67. <http://dx.doi.org/10.1108/17579881011023016>

LiaO, C.; To, P.L. y Shin, M.L. (2006). «Website practices: A comparison between the top 1000 companies in the U.S. and Taiwan». International Journal of Information Management [en línea], 26 (3), 196-211. <http://dx.doi.org/10.1016/j.ijinfomgt.2006.02.007>

Litvin, S.; Goldsmith, R. y PAN, B. (2008). «Electronic word-of-mouth in hospitality and tourism management». Tourism Management [en línea], 29, 458-468. <http://dx.doi.org/10.1016/j.tourman.2007.05.011>

López-Moreno, J.I.; Goyette, S. y Beniston, M. (2008). "Climate change prediction over complex areas: Spatial variability of uncertainties and predictions over the Pyrenees from a set of regional climate models». International Journal of Climatology [en línea], 28 (11), 1535-1550. $<$ http://dx.doi.org/10.1002/joc.1645>

López-Moreno, J.I.; Revuelto, J.; Gilaberte, M.; Morán-Tejeda, E.; Pons, M.; Jover, E.; Esteban C.; García C. y Pomeroy, J.W. (2013). «The effect of 
slope aspect on the response of snowpack to climate warming in the Pyrenees». Theoretical and Applied Climatology [en línea]. <http://dx.doi.org/10.1007/s00704-013-0991-0>

March, H.; Saurí, D. y Llurdés, J.C. (2014). "Perception of the effects of climate change in winter and summer tourist areas: The Pyrenees and the Catalan and Balearic coasts, Spain». Regional Environmental Change [en línea], 14 (3), 1189-1201. <http://dx.doi.org/10.1007/s10113-013-0561-0>

Marimon, F.; Vidgen, R.; Barnes S.J. y Cristóbal, E. (2010). «Purchasing behaviour in an online supermarket: The applicability of E-S-QUAL». International Journal of Market Research [en línea], 52 (1), 111-129. <http://dx.doi.org/10.2501/S1470785310201089>

Martínez, T.L.; Vadillo, J.A. y Bellido, N.P. (2014). «La contribución de una pequeña estación de esquí al desarrollo de su entorno: El caso de Valdezcaray (La Rioja)». Cuadernos de Turismo, 33, 151-172.

Matzler, K. y Siller, H.J. (2003). «Linking travel motivations with perceptions of destinations: The case of youth travelers in Alpine summer and winter tourism». Tourism Review [en línea], 58 (4), 6-11. <http://dx.doi.org/10.1108/eb058418>

O'Connor, P. y Frew, A. (2000). «Evaluating electronic channels of distribution in the hotel sector: A Delphi study». Information Technology and Tourism, 3 (3/4), 177-193.

Pearce, P.L. (2006). "Tourist behaviour: Themes and conceptual schemes». Annals of Tourism Research [en línea], 33 (3), 874-875. <http://dx.doi.org/10.1016/j.annals.2006.03.004>

Pechlaner, H. y Tschurtschenthaler, P. (2003). "Tourism policy, tourism organizations and change management in Alpine regions and destinations: A European Perspective». Current Issues in Tourism [en línea], 6 (6), 508-539. <http://dx.doi.org/10.1080/13683500308667967>

Pérez Pérez, M.; Martínez Sánchez, A. y Abella, S. (2002). «El sector turístico y el comercio electrónico». Boletín Económico de Información Comercial Española, 2733, 31-41.

Pons, M.; López-Moreno, J.I.; Esteban, P.; Macià, S.; Gavaldà, J.; García, C.; Rosas, M. y Jover, E. (2014). «Influencia del cambio climático en el turismo de nieve del Pirineo: Experiencia del proyecto de investigación NIVOPYR». Pirineos [en línea], 169, e006. <http://dx.doi.org/10.3989/Pirineos.2014.169006>

Puig, I. y Freire, J. (2012). Reptes i oportunitats comercials de l'adaptació al canvi climàtic a Catalunya. Barcelona: Oficina Catalana del Canvi Climàtic; Vilanova i la Geltrú: Ent Environment and Management.

Robbins, S.S. y Stylianou, A.C. (2003). «Global corporate websites: An empirical investigation of content and design». Information \& Management [en línea], 40 (3), 205-212. <http://dx.doi.org/10.1016/S0378-7206(02)00002-2>

Romagosa, F.; Priestley, G. K. y Llurdés, J. C. (2011). «El turismo en el marco de una estrategia de planificación sostenible general en Cataluña». Boletín de la asociación de geógrafos españoles, 57, 267-294.

Saurí, D. y Llurdés, J.C. (2010). El Turisme. En: Llebot, J.E. (ed.). Segon Informe sobre el Canvi Climàtic a Catalunya. Barcelona: Generalitat de Catalunya, CADS, 836-871. 
SAZ, M.I. y CARús L. (2008). «La sostenibilidad del turismo recreativo de alta montaña». Cuadernos de Desarrollo Rural, 5 (60), 11-36.

SchegG, R.; Steiner, T.; Frey, S. y Murphy, J. (2002). «Benchmarks of web site design and marketing by Swiss hotels». Information Technology and Tourism, 5 (2), 73-89.

Schmidt, S.; Cantallops, A.S. y Santos, C.P. dos (2008). «The characteristics of hotel websites and their implications for website effectiveness». International Journal of Hospitality Management [en línea], 27 (4), 504-516.

<http://dx.doi.org/10.1016/j.ijhm.2007.08.002>

SEGITTUR (2013). Estudio de mercado de apps turísticas [en línea]. <http://www. segittur.es/opencms/export/sites/segitur/.content/galerias/descargas/documentos/ Segittur_APPS-Turismo.pdf> [Consulta: 15 julio 2015].

Sigala, M. (2012). «Exploiting web 2.0 for new service development: Findings and implications from the Greek tourism industry». International Journal of Tourism Research [en línea], 14 (6), 551-566. $<$ http://dx.doi.org/10.1002/jtr.1914>

Ting, P.H.; Wang, S.T.; BaU, D.Y. y Chiang, M.L. (2013). «Website evaluation of the top 100 hotels using advanced content analysis and eMICA model». Cornell Hospitality Quarterly [en línea], 54 (3), 284-293. <http://dx.doi.org/10.1177/1938965512471892>

WalcotT, P.A. (2007). "Evaluating the readiness of e-commerce websites». International Journal of Computers, 4 (1), 263-268.

Woodside, A.G.; Ramos, V. y Duque, M. (2011). "Tourism's destination dominance and marketing website usefulness". International Journal of Contemporary Hospitality Management [en línea], 23 (4), 552-564. <http://dx.doi.org/10.1108/09596111111130038>

XiAnG, Z. y Gretzel, U. (2010). «Role of social media in online travel information search». Tourism Management [en línea], 31 (2), 179-188.

<http://dx.doi.org/10.1016/j.tourman.2009.02.016> 